\title{
Chemical Composition and Antimicrobial Activity of Leaf, Ripe and Unripe Peel of Bitter Orange (Citrus aurantium) Essential Oils
}

Fatemeh Azhdarzadeh, Mohammad Hojjati*

Department of Food Science and Technology, Ramin Agriculture and Natural Resources University of Khouzestan, Iran.

\section{A B S T R A C T}

Background and Objectives: The chemical composition and antimicrobial activity of bitter orange (Citrus aurantium) leaf, ripe and unripe peel essential oils, cultivated in southwest of Iran, were investigated.

Materials and Methods: The analysis of chemical composition of hydro-distilled essential oils was carried out by GC-MS. The disc diffusion and broth micro-dilution were used to assay the antimicrobial effect of achieved essential oils.

Results: According to the GC-MS analysis, 34, 39 and 21 components were determined in the leaf, ripe and unripe peel, respectively. The results revealed that the main components of all essential oils were linalool and limonene. The oxygenated monoterpene and hydrocarbonated monoterpene were the main chemical groups of leaf and peel essential oils, respectively. Although all of the examined essential oils had antimicrobial potential, the leaf and unripe peel essential oils with MIC of $4.67 \mathrm{mg} / \mathrm{ml}$ were the most effective against the bacteria and yeast species, respectively, and the ripe peel essential oil was the weakest one. The growth of Saccharomyces cerevisiae was controlled in the treated orange juices. The antifungal activity of essential oils was increased by rising up in their concentration and decreased by passing time. Unripe and ripe essential oils showed the strongest and weakest anti yeast potential, respectively.

Conclusions: The essential oils of leaves and ripe and unripe peels of bitter orange could be used as natural preservatives in food industry.

Keywords: Citrus aurantium, Antimicrobial, Antioxidant, Essential oil, GC-MS

\section{Introduction}

Bitter orange, Citrus aurantium, belongs to Rutaceae family and Citrus genus and is known as bitter orange or sour orange, which grows in temperate and semitropical areas. C. aurantium is a tree up to $6 \mathrm{~m}$ height, having leathery leaves and white aromatic flowers (1). It has been observed that Citrus flavonoids have wide spectrum of biological activity like antimicrobial, anticancer, antidiabetic and antioxidant (2).

The growth of microorganisms in food stuff causes spoilage and its quality deterioration (3). It has been showed the antimicrobial components by decreasing the growth rate of germ, extend food stuff shelf life (4). But the side effects of synthetic preservatives on the consumer's health and growing cases of microbial resistance to existing antibiotics have triggered attempts seeking new natural and safe substances with antimicrobial ability to eliminate synthetic preservatives $(5,6)$. Essential oils are natural, volatile and complex components of secondary metabolism of aromatic plants, which possess noteworthy antibacterial, antifungal and insecticidal potentials $(3,7)$.

Juices are fermentable, but unfermented juices, obtained by mechanical methods from matured fruits are consumed directly (8). Presence of water, sugar, vitamins and trace elements in fruit juices makes them a perfect matrix for microbial growth. Among the microorganisms, yeasts are predominant because of high acid tolerance and ability of growing in

*Address for correspondence: Mohammad Hojjati, Assistant Prof, Department of Food Science and Technology, Ramin Agriculture and Natural Resources University of Khouzestan, Iran E-mail address: hojjati@ramin.ac.ir. 
anaerobic conditions (8). Thermal pasteurization as a common method for microbial stabilization of juices reduces the product quality and freshness. Apart from thermal pasteurization, chemical preservatives are widely used to extent their shelf life. Biological activity of essential oils, especially their antimicrobial property, makes them a perfect alternate to synthetic preservatives.

To the best of our knowledge, no report has so far been published on the chemical composition and antimicrobial activity of $C$. aurantium essential oils, which grows in southwest of Iran. For these purposes, in this study, the essential oils from the leaves, and ripe and unripe peels of $C$. aurantium, cultivated in southwest of Iran, were extracted, and their chemical components were identified. Furthermore, we studied in vitro their antimicrobial effects, compared with synthetic antibiotics, including chloramphenicol and nystatin. Finally, their impact on the microbial growth of orange juice was evaluated during one week.

\section{Materials and Methods}

Plant material: Fresh leaves and (ripe and unripe) peels of $C$. aurantium were randomly harvested from 10 specified trees at Ramin Agriculture and Natural Resources University campus in Khouzestan province (southwest of Iran) in September and December 2014, respectively. A voucher specimen has been deposited at the Herbarium of the Faculty of Agriculture in this university.

Extraction of essential oil: The leaves and fruits were washed with water to remove dirt, and then peeled with a sharp knife manually. 100 gr leaves and fruit peels were placed in a $2 \mathrm{~L}$ round-bottom distillation flask, and the plant material was wetted with $1 \mathrm{~L}$ distilled water. The essential oils were obtained by hydro-distillation using clevenger-type apparatus for $3 \mathrm{~h}$. Then they were taken from upper layer dried with anhydrous sodium sulfate, passed through membrane filter (Whatman filter No. 1), and kept in low temperature $\left(4^{\circ} \mathrm{C}\right)$.

GC-MS analysis: The chemical analysis of the essential oils was performed using Agilet technology GC-6890A and GC-MSD 5975 fitted with a HP-5MS column $(30 \mathrm{~m} \times 0.25 \mathrm{~mm}$ i.d, $0.25 \mathrm{~mm}$ film thick). $0.5 \mu 1$ of essential oils were injected for analysis, and Helium was used as carrier gas at $1 \mathrm{ml} / \mathrm{min}$. The oven temperature was programmed from $60{ }^{\circ} \mathrm{C}$ to $250{ }^{\circ} \mathrm{C}$ at the $5{ }^{\circ} \mathrm{C} / \mathrm{min}$ rate, and was finally hold for $1 \mathrm{~min}$. Injector and detector temperatures were $230^{\circ} \mathrm{C}$ and
$300{ }^{\circ} \mathrm{C}$, respectively. The compounds of essential oils were identified according to GC-MS Retention time, Kovats index and Mass spectra NIST, 2013 (National Institute of Standards and Technology. http://webbook.nist.gov/chemistry/name-ser.html [accessed September 2013]). Identification was considered tentative when it was based on mass spectral data only. The essential oil components were quantified using percentage peak area calculations by means of a gas chromatograph, Agilent 6890A, with a flame ionization detector (GC-FID). The column and chromatographic conditions were the same as previously described for the GC-MS analysis. The injector temperature was $250^{\circ} \mathrm{C}$, and Helium was used as the carrier gas $(1 \mathrm{ml} / \mathrm{min})(9)$.

\section{Antimicrobial screening}

Microbial strain: Three Gram positive (Staphylococcus aureus ATCC 25923, Bacillus ceruse PTCC 1154, Streptococcus faecium ATCC 10541), and three Gram negative (Escherichia coli ATTC 25992, Salmonella typhi PTCC 1609, Shigella dysentery PTTC 188) bacterial species and one yeast (Saccharomyces cerevisiae ATTC 9763) used in this study were purchased from the Culture Collection Institute of Iranian Research Organization for Science and Technology.

Disc diffusion assay: Antimicrobial activity of the essential oils was evaluated with disc diffusion method (10). Briefly, sterile nutrient agar and yeast extract-Glucose-Chloramphenicol-agar (YGC-agar;

Merck, Darmstadt, Germany) plates were inoculated with $100 \mu \mathrm{l}$ of bacterial and yeast broth suspension $\left(10^{8} \mathrm{cfu} / \mathrm{ml}\right)$, respectively. At first, sterile discs $(6 \mathrm{~mm}$ in diameter) (Padtan Teb, Tehran, Iran) were saturated with $20 \mu 1$ of the essential oils dissolved in $10 \mu 1$ of dimethyl sulfoxide (DMSO). Then they were placed onto the medium. The plates were incubated at $37{ }^{\circ} \mathrm{C}$ for $24 \mathrm{~h}$ and $30{ }^{\circ} \mathrm{C}$ for $96 \mathrm{~h}$ for bacterial and yeast mediums, respectively. Chloramphenicol (bactericide) and Nystatin (yeasticide) were used as positive controls. After incubation time, the zones of inhibition were calculated by measuring the diameter in $\mathrm{cm}$.

Minimal inhibitory concentration assay: Minimal inhibitory concentration values of the essential oils were obtained using micro-dilution method (11) with some modification. The essential oils were dissolved in DMSO 99.9\% (Sigma Aldrich, Germany) to the highest concentration $(150 \mathrm{mg} / \mathrm{ml}$ for leaf and unripe 
Fatemeh Azhdarzadeh \& Mohammad Hojjati: Antimicrobial activity of bitter orange essential oil

peel and $200 \mathrm{mg} / \mathrm{ml}$ for ripe peel). Then serial twofold dilution were made in a concentration range from 2.34 to $150 \mathrm{mg} / \mathrm{ml}$ (leaf and unripe peel) and 3.12 to $200 \mathrm{mg} / \mathrm{ml}$ (ripe peel) in $10 \mathrm{ml}$ sterile tube containing nutrient broth and saborate dextrose broth for bacterial and yeast strains, respectively. Each well of 96-well plates contained $95 \mu 1$ of sterile media culture, $5 \mu 1$ of microbial suspension $\left(10^{8} \mathrm{cfu} / \mathrm{ml}\right)$ and $100 \mu \mathrm{l}$ from the serial dilution of essential oils. The plates were incubated at $37{ }^{\circ} \mathrm{C}$ for $24 \mathrm{~h}$ (bacterial strains) and $30{ }^{\circ} \mathrm{C}$ for $96 \mathrm{~h}$ (yeast strain). The mixture of media culture and microbial suspension was used as negative control, and chloramphenicol and nystatin were applied as standard drugs for positive control. Microbial growth was determined by the presence of a white pellet on the well bottom. The lowest essential oil concentration at which the microorganisms did not show visual growth was found as MIC.

Effect of essential oils on orange juice shelf life Orange juice preparation: To prepare the juice, the purchased oranges were washed with water and antiseptic agent and divided into two pieces. Finally, the squeezed juice was collected in sterile container.

Assessment of essential oils effectiveness on treated samples: For preparation of samples, the essential oils were added to sterile tubes containing mixture of yeast $(S$. cerevisiea $)$ suspension $\left(10^{6} \mathrm{cfu} / \mathrm{ml}\right)$ and orange juice in equal proportion (1:1) to the final concentration of 5 and $15 \mathrm{mg} / \mathrm{ml}$. Then $100 \mu 1$ of the incubated samples $\left(30{ }^{\circ} \mathrm{C}\right)$ was cultured on sterile YGC Agar plates on the days 1, 3 and 6. The results were reported after incubation time $\left(30{ }^{\circ} \mathrm{C}\right.$ for 3 to 5 days) (12).

Statistical analysis: The experiments were conducted in a completely randomized design with three replications. All data were first subjected to analysis of variance (ANOVA), after checking their normality and later to the Tukey's multiple range test to determine significant differences among the treatments at $p<0.05$. Statistical analyses were carried out using the SPSS software (ver. 20.0) (SPSS Science, Chicago, USA). The mean value of each test was calculated, and the results were expressed as mean \pm standard deviation (SD).

\section{Results}

Chemical composition of bitter orange essential oils: The GC-MS analysis results of $C$. aurantium oils are summarized in Table 1.
Table 1. Chemical composition of $C$. aurantium leaf, unripe and ripe peel from southwest of Iran

\begin{tabular}{|c|c|c|c|c|}
\hline Compound & $\mathrm{KI}^{\mathrm{a}}$ & $\begin{array}{c}\text { Leaf }^{\mathrm{b}} \\
\%\end{array}$ & $\begin{array}{l}\text { Unripe } \\
\text { peel }^{\mathrm{b}} \%\end{array}$ & $\begin{array}{l}\text { Ripe } \\
\text { peel }^{\mathrm{b}} \%\end{array}$ \\
\hline alpha thujene & 926 & - & - & 0.01 \\
\hline alpha pinene & 939 & 0.18 & 2.56 & 1.96 \\
\hline Camphene & 949 & 0.12 & - & 0.02 \\
\hline Sabinene & 972 & 0.34 & 0.52 & 0.46 \\
\hline beta pinene & 980 & 2.22 & 0.51 & 0.56 \\
\hline beta myrcene & 994 & 3.49 & 3.93 & 5.74 \\
\hline Octanal & 1001 & - & 0.39 & 0.83 \\
\hline delta 3 carene & 1010 & 0.05 & - & - \\
\hline alpha terpinene & 1020 & 0.12 & - & 0.02 \\
\hline p cymene & 1024 & - & 0.06 & - \\
\hline limonene & 1034 & 4.67 & 59.88 & 81.6 \\
\hline 1,8 cineole & 1037 & - & - & 0.07 \\
\hline cis beta ocimene & 1040 & 2.09 & - & 0.52 \\
\hline trans beta ocimene & 1055 & 4.24 & - & - \\
\hline gamma terpinene & 1064 & 0.15 & - & 0.05 \\
\hline 2- octenal & 1065 & - & - & 0.01 \\
\hline 1-octanol & 1068 & - & - & 0.13 \\
\hline linalool oxide & 1092 & 0.05 & - & 0.94 \\
\hline terpinolene & 1099 & 1.42 & - & - \\
\hline alpha terpinolene & 1100 & - & - & 0.05 \\
\hline Linalool & 1110 & 32.6 & 1.33 & 2.19 \\
\hline Nonanal & 1104 & - & - & 0.07 \\
\hline trans-p-2 8-menthadien-1-ol & 1105 & - & 0.83 & - \\
\hline cis limonene oxide & 1112 & - & 3.63 & - \\
\hline trans limonene oxide & 1125 & - & 1.48 & - \\
\hline Alloocimene & 1139 & 0.04 & - & - \\
\hline citronellal & 1160 & 0.03 & - & 0.02 \\
\hline 4- terpineol & 1180 & 0.39 & - & 0.15 \\
\hline alpha terpineol & 1190 & 17.24 & 0.52 & 1.03 \\
\hline dihydrocarvone & 1193 & - & - & 0.02 \\
\hline decenal & 1214 & - & 0.56 & 0.5 \\
\hline trans carveol & 1215 & - & 2.48 & 0.05 \\
\hline cis carveol & 1222 & - & 1.27 & - \\
\hline Nerol & 1235 & 3.62 & - & 0.23 \\
\hline carvone & 1242 & - & 2.52 & 0.01 \\
\hline carvol & 1245 & 0.16 & - & - \\
\hline linalyl acetate & 1255 & 13.26 & 0.52 & - \\
\hline Citral & 1268 & - & - & 0.45 \\
\hline perilla alcohol & 1300 & - & 0.63 & 0.03 \\
\hline 4- vinylguaiacol & 1316 & 0.09 & - & - \\
\hline 2,4 decadenial & 1320 & - & - & 0.04 \\
\hline Alpha-Terpenyl acetate & 1367 & 0.2 & - & - \\
\hline neryl acetate & 1369 & 4.68 & - & 0.12 \\
\hline geranyl acetate & 1383 & 7.3 & 2.09 & 0.33 \\
\hline trans caryophyllene & 1422 & 0.18 & - & 0.22 \\
\hline alloaromadendrene & 1455 & - & 5.88 & - \\
\hline alpha humulene & 1480 & 0.04 & - & 0.02 \\
\hline Germacrene-D & 1480 & - & - & 0.22 \\
\hline bicyclogermacrene & 1486 & 0.14 & - & 0.02 \\
\hline delta Cadinene & 1523 & 0.04 & - & 0.01 \\
\hline Germacrene B & 1551 & - & - & 0.02 \\
\hline trans nerolidol & 1560 & 0.11 & - & 0.09 \\
\hline caryophyllene oxide & 1581 & - & 1.61 & - \\
\hline Spathulenol & 1582 & 0.04 & - & - \\
\hline Viridiflorol & 1588 & 0.06 & - & - \\
\hline T-Cadinol & 1634 & 0.05 & - & - \\
\hline T-Muurolol & 1647 & 0.064 & - & - \\
\hline Nootkatone & 1815 & - & - & 0.02 \\
\hline monoterpene hydrocarbons & & 19.09 & 67.85 & 91.76 \\
\hline oxygenated monoterpenes & & 79.53 & 16.47 & 5.69 \\
\hline sesquiterpene hydrocarbons & & 0.4 & & 0.6 \\
\hline oxynenated sesquiterpens & & 0.324 & 7.49 & 0.02 \\
\hline Others & & 0.13 & 1.39 & 0.75 \\
\hline Total & & 99.47 & 93.21 & 98.83 \\
\hline
\end{tabular}

${ }^{\mathrm{a}}$ Kovats Index; ${ }^{\mathrm{b}}$ relative percentage 
The hydro-distilled bitter orange leaf, unripe and ripe fruit peel essential oils were obtained in the yield of $0.07,0.66$ and $0.86 \%$, respectively. Based on Table 1, 34 constituents $(99.47 \%$ of the total oil), 39 components $(98.83 \%$ of the total oil) and 21 constituents (93.21\% of the total oil) were identified from the oils of bitter orange leaf (petitgrain), and ripe and unripe fruit peels, respectively. According to the data, leaf oil was found rich in oxygenated monoterpenes $(80.95 \%)$, whereas unripe and ripe peel essential oils were rich in monoterpene hydrocarbons $(67.85 \%$ and $91.85 \%)$.

In addition, based on our findings, the major components of the leaf essential oil were linalool (32.60\%) and alpha terpineol (17.24\%), whereas the main constituent of peel essential oil was limonene (59.88\% and 81.6\%), which followed by alloaromadenderene $(5.88 \%)$ and beta myrcene (5.74\%) for unripe and ripe peel oils, respectively.
Antimicrobial assay: The obtained data from disc diffusion in $20 \mu \mathrm{l}$ are summarized in Table 2 . Although the growth of all tested microorganisms were inhibited with three essential oils, results on their antimicrobial activity indicated that $B$. cereus and $S$. dysentery were the most sensitive and $E$. coli and $S$. typhi were the most resistant microorganisms to the essential oils (Table 2).

Furthermore, on the basis of the data given in Table 2 and 3, the unripe and ripe peel oils of sour orange fruit proved to have the strongest and weakest antimicrobial activity, respectively.

Essential oils effectiveness on the growth of $S$. cerevisiea in inoculated orange juice: Based on the obtained data (Table 4), all the three essential oils significantly inhibited the growth of $S$. cerevisiae in the treated samples in comparison to the control sample. Also, by increasing in the essential oils' concentration, their antifungal activity showed an increasing trend.

Table 2. Antimicrobial activity of $C$. aurantium leaf, unripe and ripe peel essential oil and standard antibiotics against tested microorganisms by Disc diffusion method (IZ in $\mathrm{cm})^{\mathrm{a}, \mathrm{b}}$

\begin{tabular}{|c|c|c|c|c|c|}
\hline \multirow{2}{*}{ Microorganisms } & \multicolumn{3}{|c|}{ Essential oil } & \multicolumn{2}{|c|}{ Standard antibiotics } \\
\hline & leaf & Unripe peel & ripe peel & Chloramphenicol & Nystatin \\
\hline B. cereus & $3.45 \pm 0.15^{\mathrm{Ab}}$ & $4.50 \pm 0.70^{\mathrm{ABa}}$ & $2.95 \pm 0.55^{\mathrm{Ac}}$ & $3.26 \pm 0.25^{\mathrm{ABb}}$ & - \\
\hline S. aureus & $2.55 \pm 0.25^{\mathrm{Cb}}$ & $3.52 \pm 0.07^{\mathrm{CDa}}$ & $2.31 \pm 0.16^{\mathrm{ABb}}$ & $3.50 \pm 0.0^{\mathrm{Aa}}$ & - \\
\hline S. faecium & $3.00 \pm 0.30^{\mathrm{Bb}}$ & $3.55 \pm 0.25^{\mathrm{CDa}}$ & $2.46 \pm 0.15^{\mathrm{ABc}}$ & $3.00 \pm 0.0^{\mathrm{ABb}}$ & - \\
\hline E. coli & $1.7 \pm 0.0^{\mathrm{Dc}}$ & $3.97 \pm 0.07^{\mathrm{BCa}}$ & $0.93 \pm 0.23^{\mathrm{Dd}}$ & $2.40 \pm 0.08^{\mathrm{Bb}}$ & - \\
\hline S. dysentery & $2.00 \pm 0.20^{\mathrm{Db}}$ & $4.60 \pm 0.30^{\mathrm{Aa}}$ & $1.53 \pm 0.75^{\mathrm{CDb}}$ & $2.00 \pm 0.0^{\mathrm{Cb}}$ & - \\
\hline S. typhi & $3.21 \pm 0.12^{\mathrm{ABa}}$ & $2.17 \pm 0.17^{\mathrm{Eb}}$ & $1.46 \pm 0.27^{\mathrm{Dc}}$ & $2.25 \pm 0.25^{\mathrm{ABb}}$ & - \\
\hline S. cerevisiae & $2.50 \pm 0.30^{\mathrm{Cc}}$ & $3.12 \pm 0.12^{\mathrm{Db}}$ & $2.18 \pm 0.20^{\mathrm{BCc}}$ & - & $4.15 \pm 0.28^{\mathrm{a}}$ \\
\hline
\end{tabular}

Table 3. Antimicrobial activity of $C$. aurantium leaf, unripe and ripe peel essential oil (mg/ml) and standard antibiotics against tested microorganisms by micro-dilution method ${ }^{\text {a,b,c }}$

\begin{tabular}{|c|c|c|c|c|c|}
\hline \multirow{2}{*}{ Microorganisms } & \multicolumn{3}{|c|}{ Essential oil } & \multicolumn{2}{|c|}{ Standard antibiotics } \\
\hline & Leaf & Unripe peel & Ripe peel & Chloramphenicol & Nystatin \\
\hline B. cereus & $9.37 \pm 0.12^{\mathrm{Bc}}$ & $37.5 \pm 2.17^{\mathrm{Bb}}$ & $50 \pm 1.32^{\mathrm{Ba}}$ & $37.5 \pm 0^{\mathrm{Ab}}$ & - \\
\hline S. aureus & $18.75 \pm 0.11^{\mathrm{Ac}}$ & $37.5 \pm 1.03^{\mathrm{Bb}}$ & $100 \pm 5.16^{\mathrm{Aa}}$ & $37.5 \pm 0^{\mathrm{Ab}}$ & - \\
\hline S. faecium & $18.75 \pm 0.21^{\mathrm{Ac}}$ & $37.5 \pm 0.82^{\mathrm{Bb}}$ & $100 \pm 4.15^{\mathrm{Aa}}$ & $37.5 \pm 0^{\mathrm{Ab}}$ & - \\
\hline E. coli & $4.67 \pm 0.14^{\mathrm{Cc}}$ & $37.5 \pm 1.18^{\mathrm{Bb}}$ & $50 \pm 2.65^{\mathrm{Ba}}$ & $37.5 \pm 0^{\mathrm{Ab}}$ & - \\
\hline S. dysentery & $9.37 \pm 0.17^{\mathrm{Bc}}$ & $37.5 \pm 1.58^{\mathrm{Bb}}$ & $100 \pm 3.45^{\mathrm{Aa}}$ & $37.5 \pm 0^{\mathrm{Ab}}$ & - \\
\hline S. typhi & $18.75 \pm 2.21^{\mathrm{Ad}}$ & $75 \pm 3.67^{\mathrm{Aa}}$ & $50 \pm 2.12^{\mathrm{Bb}}$ & $37.5 \pm 0^{\mathrm{Ac}}$ & - \\
\hline S. cerevisiae & $9.37 \pm 0.18^{\mathrm{Bb}}$ & $4.67 \pm 0.10^{\mathrm{cc}}$ & $25 \pm 1.37^{\mathrm{Ca}}$ & - & $4.67 \pm 0^{\mathrm{d}}$ \\
\hline
\end{tabular}

${ }^{a}$ Standards antibiotics were used in concentration of $150 \mu \mathrm{g} / \mathrm{ml} ;{ }^{b}$ values represent mean \pm SD of three replicates; ${ }^{\mathrm{c}}$ Within columns and rows, means followed by the same capital and small letter are not significantly different according to Tukey's test (0.05), respectively. 
Fatemeh Azhdarzadeh \& Mohammad Hojjati: Antimicrobial activity of bitter orange essential oil

Table 4. Leaf, ripe and unripe peel C. aurantium essential oils effectiveness on $S$. cerevisiae inoculated orange juice shelf life ${ }^{\text {ab }}$

\begin{tabular}{|c|c|c|c|c|c|c|c|}
\hline \multirow{2}{*}{ Colony count } & \multicolumn{2}{|c|}{ Leaf } & \multicolumn{2}{|c|}{ Unripe peel } & \multicolumn{2}{|c|}{ Ripe peel } & \multirow{2}{*}{ control } \\
\hline & $5 \mathrm{mg} / \mathrm{ml}$ & $15 \mathrm{mg} / \mathrm{ml}$ & $5 \mathrm{mg} / \mathrm{ml}$ & $15 \mathrm{mg} / \mathrm{ml}$ & $5 \mathrm{mg} / \mathrm{ml}$ & $15 \mathrm{mg} / \mathrm{ml}$ & \\
\hline Day 1 & $0^{\mathrm{Ba}}$ & $0^{\mathrm{Aa}}$ & $0^{\mathrm{Ba}}$ & $0^{\mathrm{Aa}}$ & $0^{\mathrm{Ba}}$ & $0^{\mathrm{Aa}}$ & N.D \\
\hline Day 3 & $0^{\mathrm{Ba}}$ & $0^{\mathrm{Aa}}$ & $0^{\mathrm{Ba}}$ & $0^{\mathrm{Aa}}$ & $0^{\mathrm{Bb}}$ & $0^{\mathrm{Ab}}$ & N.D \\
\hline Day 6 & $91 \pm 8.45^{\mathrm{Ab}}$ & $0^{\mathrm{Ab}}$ & $56.32 \pm 7.09^{\mathrm{Ac}}$ & $0^{\mathrm{Ad}}$ & $344 \pm 30.55^{\mathrm{Aa}}$ & $0^{\mathrm{Ad}}$ & N.D \\
\hline
\end{tabular}

\section{Discussion}

Chemical composition of bitter orange essential

oils: The results of GC-MS analysis seem to be in agreement with those reported before in the literature (7, 12-14), which introduced oxygenated monoterpenes and monoterpene hydrocarbons as the main chemical groups of leaf and peel oils, respectively.

Several studies on the chemical composition of $C$. aurantium essential oils seem to be matched with our observation $(16,17)$. GC-MS analysis of bitter orange leaf oil of north of Iran showed that linalool, linalyl acetate and alpha terpineol were the main components of the oil (16). Hashemi et al. (2014) reported that linalool and alpha tepineol as the major compositions of C. aurantium leaf essential oil grown in Khouzestan (17).

Previous studies have shown that the amount of limonene in bitter orange peel essential oils is in majority (2, 13-14, 18). Moreover, Sarrow et al. (2013) reported that limonene $(94.67 \%)$, myrcene $(2 \%)$ and linalool $(0.67 \%)$ were the main components of bitter orange ripe peel essential oil, grown in Greece.

Comparison of limonene content of the peels essential oils (Table 1) indicates that the amount of limonene was increased during the fruit maturation, which is in agreement with the results of Bourgou et al. (2012) in Tunisia. The variation in limonene content, from $59.88 \%$ to $91.76 \%$, is possibly because of the decomposition of linalool and its acetate (13).

Although our findings in this study followed well by previous documents, the differences between the quality and quantity of essential oils' volatile components, may be due to genetic, environmental, climate, geographical, growing stage and seasonal variations (17).
Antimicrobial assay: According to the Table 2, the bacterial species showed different levels of susceptibility to these three essential oils (E. coli was the most resistant strain to leaf and ripe essential oils, while the unripe essential oil had the weakest effectiveness on $S$. typhi). These observations can be described by: 1) the different composition of essential oils, showing different antibacterial activity; different compounds have different targets in bacterial cells. 2) Although, the exact mechanism of the essential oils' antibacterial activity is still unknown, the Gramnegative bacteria are slightly more resistance to essential oils than Gram-positive ones. The outer layer in Gram-negative bacteria, which covers the peptidoglycan layer, may be the reason for the low susceptibility of this group of bacteria to essential oils.

These results are supported by the findings of others $(2,19)$. Ben Hsoun et al. (2013) introduced that B. cereus as the most sensitive strain after Listeria to neriol oil, and Trabelsi et al. (2014) mentioned that $E$. coli was the most resistant strain to $C$. aurantium ripe peel essential oil. Skovic et al. (2010), also documented that antimicrobial effect of $C$. aurantium ripe peel essential oil was weaker than the unripe one.

Since essential oils have various components, their ability to inhibit the growth of microorganisms is significantly different. Oxygenated monoterpenes are compounds with high antimicrobial activity (21); therefore, the higher oxygenated monoterpenic content causes higher antimicrobial property. According to GC-MS analysis (Table 1), the oxygenated monoterpenic content of unripe peel essential oil is higher than the ripe one. Similar observations were reported by Griffin et al. (2000) in which the low amount of oxygenated monoterpenes in 
ripe peel was claimed to be responsible for its weaker antimicrobial activity.

The results of micro-dilution assay are shown in Table 3. As presented in this table, petitgrain and unripe peel oils have the most antibacterial and antifungal property, and the ripe peel oil exhibit the weakest antimicrobial activity. Although the oxygenated components content of petitgrain oil were higher than the unripe peel oil, the presence of two oxygenated sesquiterpenes (alloaromadenderen and caryophillene oxide) in unripe peel oil plays an important role in its antifungal activity.

Comparison of two different essential oils of Lanceolata Barks (different extraction time) by Sousa et al. (2012) demonstrated that the essential oil with more caryophyllene oxide content has more antifungal property. By the way, Mulyaningsih et al. (2010) stated that antifungal activity of the essential oil of Eucalyptus glubulus was the same as pure alloaromadenderen (one of the key components of the mentioned essential oil), whereas another major composition of the essential oil, 1,8 cineol, exhibited lower antifungal activity.

On the other hand, the differences between obtained results of these two antimicrobial assay methods (Disc diffusion assay and Minimal inhibitory concentration assay) could be attributed to the variety of essential oils' solubility and diffusion rate in the Agar medium or their volatilization (25).

In addition, our study confirmed that both Gram positive and Gram negative bacteria were sensitive to all essential oils; this is in agreement with the findings of Hindi and Chabuck (2010). The mechanism of essential oil revenue is not completely found. However, some papers have reported that the hydrophobicity of essential oils enables them to break down the lipids of the cytoplasmic membrane and mitochondria, rendering the cell membranes permeable and leading to the leakage of cell contents $(5,27)$.

Essential oils effectiveness on the growth of $S$. cerevisiea in inoculated orange juice: These results are supported by Ndagijimana et al.'s (2004) observations when treated orange juice with the mentioned essential oils. As they mentioned, treatment of orange juice with orange essential oil reduced growth of $S$. cerevisiae samples. Based on what Tserennadmid et al. (2011) stated, the lemon essential oil inhibited the growth of $S$. cerevisiae in transparent apple juice.

As explained before, in presence of essential oil, the amount of energy required for cell improvement was increased; consequently, the lag phase of microbial growth and fermentation time was extended (29-31). Our results further demonstrated that storage period had significant effect on the orange juice yeast population (Table 4); this finding is supported by Rehman et al.'s study (2007) in which there was a direct relationship between passing of time (during 6 days) and yeast colony count.

Overall, we can say that a greater concentration of essential oil is needed to achieve the same effect in food (27); however, orange juice has relatively more pure and homogeneous matrix than other foods. Accordingly, the low concentration of yeast suspension, low oxygen content and presence of vitamin $\mathrm{C}$ in orange juice may cause lower concentration of essential oils (Tables 3 and 4). The antimicrobial activity of essential oils is affected by the degree to which oxygen is available. This could be due to the fact that when little oxygen is present, fewer oxidative changes can take place in the essential oil (27).

Conclusion: In conclusion, our results demonstrated that essential oils of $C$. aurantium leaf and (ripe and unripe) peel have antimicrobial activities, but they enjoy different degrees of antimicrobial abilities. The high in vitro antimicrobial activity of bitter orange leaf oil could be attributed to the presence of high amount of oxynated monoterpenes such as linalool, alpha terpineol, and linalyl acetate. Also, through the results of this study, we can conclude that the antimicrobial ability promoted by the essential oil of C. aurantium unripe peel is due to the presence of limonene, which accounts for about $59.88 \%$ of its composition.

Finally, our study revealed that essential oils of $C$. aurantium unripe and ripe peels exhibited the strongest and weakest antifungal activity in orange juice, respectively, as confirmed by the micro-dilution assay result.

The findings of this work further indicated that bitter orange leaf and unripe peel essential oils can be considered for future utilization as a potential source 
of natural preservative to eliminate the growth of some foodborne pathogens and enhance food shelf life. Further research is needed to investigate their toxicity.

\section{Financial disclosure}

The authors declared no financial interest.

\section{Funding/Support}

This research was done with the financial support by Ramin Agriculture and Natural Resources University of Khuzestan, Iran.

\section{References}

1. Azadi B, Nichavar B, Amin CH. Volatile constituent of the peel and leaf of Citrus aurantium L. cultivated in the north of Iran. J Pharm Health Sci 2012; 1(3): 37-41.

2. Ben Hsoun A, Hamdi N, Benttalina N, Abdelkafi. Characterization of essential oil from Citrus aurantium L. floweres: Antimicrobial and Antioxidant activities. J Oleo Sci 2013; 662(10): 763-772.

3. Celiktas OY, Kocabas EEH, Bedir E, Sukan FV, Ozek T, Baser KHC. Antimicrobial activities of methanol extracts and essential oils of Rosmarinus oficinalis depending on location and seasonal variation. Food Chem 2007; 100(2): 553-559.

4. Azadi B, Nichavar B, Amin CH. Volatile constituent of the peel and leaf of Citrus aurantium L. cultivated in the north of Iran. J Pharm Health Sci 2012; 1(3): 37-41.

5. Ben Hsoun A, Hamdi N, Benttalina N, Abdelkafi. Characterization of essential oil from Citrus aurantium L. floweres: Antimicrobial and Antioxidant activities. J Oleo Sci 2013; 662(10): 763-772.

6. Celiktas OY, Kocabas EEH, Bedir E, Sukan FV, Ozek T, Baser KHC. Antimicrobial activities of methanol extracts and essential oils of Rosmarinus oficinalis depending on location and seasonal variation. Food Chem 2007; 100(2): 553-559.

7. Beuchat LR, Golden DA. Antimicrobials occurring naturally in foods. Food Technol 1989; 43(1): 134-142.

8. Knobloch K, Pauli A, Iberi B, Weigand H, Weis N. Antibacterial and antifungal properties of essential oil components. J Essent Oil Res 1989; 1(3): 119-128.

9. Ebrahimabadi AH, Ebrahimabadi EH, Djafari- Bidgoli Z, Jokar Kashani F, Mazoochi A, Bahooli H. Composition and antioxidant and antimicrobial activity of the essential oil extracts of Stachys inflate Benth from Iran. Food Chem 2010; 119(2): 452- 458.

10. Bakkali F, Avebeck S, Avebeck D, Idaomar M. Biological effects of essential oils - A review. Food Chem Toxicol 2008; 46(2): 446-475.

11. Bevilacqua A, Corbo MR, Campanielli D, Amato DD, Gallo M, Speranza B, Sinigaglia M. Shelf life prolongation of fruit juices through essential oils and homogenization. In: Mendez-Vilas, A editor. Science against Microbial Pathogens: Communicating Current Research and Technological Advances. 3rd ed. Vol. 2. Spain: Formatex Research Center; 2011: 1157-1166.

12. Zandi-Sohani N, Hojjati M, Carbonell-Barrachina AA. Volatile Composition of the Essential Oil of Callistemon citrinus Leaves from Iran. J Essent Oil Bear Pl 2012; 15(5): 703-707.

13. Owlia P, Saderi H, Rasooli I, Sefidkon F. Antimicrobial characteristics of same herbal oils on Pseudomonas aeruginosa with special reference to their chemical composition. Iranian J Pharm Res 2010; 8(2): 107-114.

14. Gülluce M, Sokmen M, Sahin F, Sokmen A, Adlguzel A, Ozer H. Biological activity of the essential oil and methanolic extract of Micromeria fruiticosa (L) Druce spp Serphyllifolia (Bieb) $\mathrm{pH}$ Davis plants from the eastern Anatolia region of Turkey. J Science Food Agric 2004; 84(7): 735-741.

15. Institute of Standards and Industrial Research of Iran, number 3414. 2006. Soft drinks-Fruit juice and Fruit juice products-Microbiological Specification and test methods. 1-8.

16. Boelens MH, Jimenez R. The chemical composition of the peel oils from unripe and ripe fruits of bitter orang (Citrus aurantium L. Ssp. Amara Engl). Flavour Frag J 1989; 4(3): 139-142.

17. Bourgou S, Rahali FZ, Ourghemmi I, Tounsi MS. Changes of peel essential oil composition of four Tunisian citrus during fruit maturation. Sci World J 2012; 1-10

18. Sarrow E, Chatzopoulou P, Dimassi-Theriou K, Therios I. Volatile constituents and antioxidant activity of peel, flower and leaf oils of Citrus aurantium L. growing in Greece. Molecule 2013; 18(9): 1063910647.

19. Mosaddegh M, Kamalinejad M, Dehmaoobad Sharifabadi A, Esfahani B. Composition of the volatile oils of the Citrus bigaradia, Citrus limon and Citrus delisiosa. J Med Plant 2004; 3(11): 25-30.

20. Hashemi Z, Hojjati M, Tahanezhad M. Extractin and identification of essential oil components from (Citrus aurantium) leaf and evaluation of its antioxidant activity. J Innov Food Sci Technol 2014; 2(6): 47-61.

21. Periyanayagam K, Dhanalakshmi S, Karthikeyan V, Jagadeesan M. Phytochemical studies and GC/MS analysis on the isolated essential oil from the leaves of Citrus aurantium Linn. J Nat Prod Plant Resour 2013; 3(6): 19-23.

22. Trabelsi D, Ammar A, Bouabdallah F, Zagrouba F. Antioxidant and antimicrobial activities of essential oils and methanolic extracts of Tunisian Citrus aurantium L. J Environment Sci Toxicol Food Technol 2014; 8(5): $18-27$.

23. Skovic M, Glamoclija J, Marin PD, Brkic D, Van Grien Sven LJLD. Antibacterial effects of the essential oils of 
commonly consumed medicinal herbs using an in vitro model. Molecule 2010; 15(11): 7532-7546.

24. Kotan R, Kordali S, Cakir A. Screening of antibacterial activities of twenty-one oxygenated monoterpenes. $\mathrm{Z}$. Naturforsch C 2007; 62(7/8): 507.

25. Griffin GS, Makham LJ, Leach ND. An agar dilution method for determination of the minimum inhibitory concentration of essential oils. J Essent oil Res 2000; 12(2): 249-255.

26. Sousa OV, Del - Vechio - Vieira G, Alves MS, Araujo AAL, Pinto MAO, Amaral MPH, etal. Chemical composition and biological activities of the essential oils from Duguetia lanceolata St. Hil. Barks. Molecule 2012; 17(9): 11056-11066.

27. Mulyaningsih S, Sporer F, Zimmermann S, Reichling J, Wink M. Synergistic properties of the terpenoids aromadrendrene and 1,8 - cineol from the essential oil of Eucalyptus globulus against antibiotic - susceptible and antibiotic - resistant pathogen. Phytomedicine 2010; 17(13): 1061-1066.

28. Hindi NKK, Chabuck ZAG. Antimicrobial activity of different aqueous Lemon extracts. J App Pharm Sci 2013; 3(6): 074-078.

29. Gopal PV. Evaluation of antimicrobial activity of Citrus aurantium against some Gram negative bacterial strain. Pharmacia 2012; 1(3): 107-109.
30. Burt S. Essential oils: their antibacterial properties and potential application in food - A review. Int $\mathrm{J}$ Food Microbiol 2004; 94(3): 223-253.

31. Ndagijimana M, Belletti N, Lanciohi R, Guerzoni ME, Gardini F. Effect of aroma compounds on the microbial stabilization of orange - based soft drinks. J Food Sci 2004; 69(1): 20-24.

32. Tserennadmid R, Tako M, Galgoczy C, Papp T, Pesti M, Vagvolgyi C, et al. Anti yeast activities of some essential oils in growth media, fruit juices and milk. Int J Food Microbiol 2011; 144(3): 480-486.

33. Bouhdid S, Abrinin J, Zhiri A, Espuny MJ, Munresa A. Investigation of functional and morphological changes in Pseudomonas aeruginosa and Staphylococcus aureus cells induced by Origanum compatum essential oil. J App Microbiol 2009; 106(5): 1558-1568.

34. Papanikolaou S, Gortiz O, Margeli E, Chinou L, Galiotou - Panayoyou, M, Lalas S. Effect of citrus essential oil addition upon growth and cellular lipids of Yarrowia lipolytica yeast. Eur J Lipid Sci Tech 2008; 110(11): 997-1006.

35. Rehman S, Hussain S, Nawaz H, Ahmad MM, Murtaza MM. Inhibitory effect of citrus peel essential oils on the microbial growth of bread. Pak J Nutr 2007; 6(6): 558561. 